\title{
Allometric biomass equations of Larix sibirica in the Altay Mountains, Northwest China
}

\author{
LI Yuanyuan ${ }^{1,2}$, LIU Qijing ${ }^{1 *}$, MENG Shengwang ${ }^{3}$, ZHOU Guang ${ }^{1}$ \\ ${ }^{1}$ Key Laboratory of Forest Cultivation, Department of Forest Sciences, Beijing Forestry University, Beijing 100083, China; \\ ${ }^{2}$ Agricultural College, Shihezi University, Shihezi 832000, China; \\ ${ }^{3}$ Qianyanzhou Ecological Research Station, Key Laboratory of Ecosystem Network Observation and Modeling, Institute of \\ Geographic Sciences and Natural Resources Research, Chinese Academy of Sciences, Beijing 100101, China
}

\begin{abstract}
Boreal forests are important carbon sinks and have tremendous potential to mitigate climate change. Aboveground biomass of Siberian larch (Larix sibirica Ledeb.) stands in the Altay Mountains, Northwest China was studied and allometric equations that are related to the biomass of aboveground components using diameter at breast height $(\mathrm{DBH})$ or both $\mathrm{DBH}$ and height $(\mathrm{H})$ as independent variables for $L$. sibirica trees were derived in this paper. A linear simultaneous equation system by using either DBH or both $\mathrm{DBH}$ and $\mathrm{H}(\mathrm{DBH} \& \mathrm{H})$ indices, was used to ensure additivity of the biomass of individual tree components, and was fitted for L. sibirica. Model performance was validated using the jackknifing test. Results indicate that the goodness-of-fit for the regressions was lowest for the needles $\left(R^{2}\right.$ ranging from 0.696 to 0.756 ), and highest for the stem wood ( $R^{2}$ ranging from 0.984 to 0.997$)$ and the aggregated biomass components ( $R^{2}$ ranging from 0.994 to 0.995 ). The coefficient of determination for each component was only marginally improved in terms of model fit and performance in the biomass equations that used $\mathrm{DBH} \& \mathrm{H}$ as the independent variables compared to that used $\mathrm{DBH}$ as the independent variable, and needles yielded an even worse fit. Stem biomass accounted for the largest proportion $(87 \%)$ of the aboveground biomass. Based on the additive equations that used DBH as the single predicitor in this study, the mean aboveground carbon stock density and the carbon storage values of L. sibirica forests were $74.07 \mathrm{Mg} \mathrm{C} / \mathrm{hm}^{2}$ and $30.69 \mathrm{Tg} \mathrm{C}$, respectively, in the Altay Mountains. Empirical comparisons of published equations for the same species growing in the Altay Mountains of Mongolia were also presented. The mean aboveground carbon stock density estimated for $L$. sibirica forests was higher in the Chinese Altay Mountains than in the Mongolian Altay Mountains $\left(66.00 \mathrm{Mg} \mathrm{C} / \mathrm{hm}^{2}\right)$.
\end{abstract}

Keywords: Larix sibirica; additive equation; allometric equation; nested regression method; carbon storage

Citation: LI Yuanyuan, LIU Qijing, MENG Shengwang, ZHOU Guang. 2019. Allometric biomass equations of Larix sibirica in the Altay Mountains, Northwest China. Journal of Arid Land, 11(4): 608-622. https://doi.org/10.1007/s40333-019-0023-8

\section{Introduction}

Forests are more important terrestrial carbon sinks than any other ecosystems on the globe, in which boreal forest biome represents one of most important terrestrial carbon stores and is very sensitive and vulnerable to regional and global warming (BonAltayan, 2008; Dulamsuren et al., 2016). For example, Jarvis and Linder (2000) found that the productivity of boreal forests has been thought to benefit from climate warming. However, Tei et al. (2014) suggested that boreal forests (i.e., larch-dominated) respond to climate warming by reduced productivity. Mountain forest is largely subjected to global climate change, especially change in the form of warming

*Corresponding author: LIU Qijing (E-mail: liuqijing@bjfu.edu.cn)

Received 2017-11-20; revised 2018-05-16; accepted 2018-08-07

C Xinjiang Institute of Ecology and Geography, Chinese Academy of Sciences, Science Press and Springer-Verlag GmbH Germany, part of Springer Nature 2019 
(Chauchard et al., 2010). In recent years, the quantity, distribution, and dynamics of forest carbon storage have been of great significance to research on global climate change and carbon cycles (Pan et al., 2011). Generally, forest carbon stocks can be estimated via estimation of tree biomass (Hall et al., 2006), and tree biomass is typically derived from the quantity of aboveground biomass by assuming that $50 \%$ of the biomass is composed of carbon (Basuki et al., 2009; Goetz et al., 2009). Therefore, accurately estimating tree and stand biomass is essential for quantifying forest carbon sequestration, and tracking carbon cycling between the atmosphere and the terrestrial biosphere in relation to global climate change (Cairns et al., 2000; Fang et al., 2001; Wang, 2006; Picard et al., 2012; Dong et al., 2015). On the other hand, tree-level biomass equations are basic tools for converting inventory plot data into biomass density (Zianis and Mencuccini, 2004; Lambert et al., 2005; Pérez-Cruzado and Rodríguez-Soalleiro, 2011).

Destructive methods are generally used for the determination of tree biomass via selecting standard trees and weighting them directly in the field (Ketterings et al., 2001; Alvarez et al., 2012; Anitha et al., 2015). Direct weighing is simple, but it is time-consuming and costly (Son et al., 2001). Furthermore, particularly for large trees, it is almost impossible to obtain root and crown biomass (Liu, 2009). However, allometric equations are efficient in that they require less labor and time and can provide accurate and reliable non-destructive estimates of the total and components biomass (Dong et al., 2015; Riofrío et al., 2015; Kuyah et al., 2016). The development of allometric equations requires trees to be harvested and weighed, and these data are then linked to tree structure variables, such as diameter at breast height (DBH), height (H), and other dendrometric variables (Anitha et al., 2015). DBH is an essential variable in all biomass models (Xu et al., 2016), and 55\% of the current equations are based on this metric (Anitha et al., 2015). Wood-specific density and tree crown dimensions are used as additional measures to improve the accuracy of biomass equations (Kuyah et al., 2016; Xu et al., 2016). In practice, most allometric equations employ DBH as the only independent variable (Gower et al., 2007). This is probably because DBH can be easily and accurately measured in the field. However, since the relationship between biomass and DBH is nonlinear, the use of only one index may not be able to represent the natural variation in a forest stand with a large area (Tsogt and Lin, 2014). Studies have shown that adding tree height into biomass equations can improve the fit and performance of a model (Wang, 2006; Li and Zhao, 2013; Xu et al., 2016). H has also been shown to be a promising individual predictor both for species-specific and general equations (Blujdea et al., 2012). In the field, it is labor intensive to harvest and weigh branches and foliage. Liu (2009) established a nested regression method based on the volume of branches and the quantity of foliage which data are nested, thus reducing the number of measured samples. Jia et al. (2015) and Meng et al. (2017) estimated aboveground and belowground biomass of Pinus tabuliformis and developed two dominant deciduous tree biomass equations using above nested regression method, respectively, indicating that the method is reliable.

In tree biomass estimations, it is important to consider the property of additivity, i.e., the sum of the biomass predictions of components may not equal to the total biomass prediction (Parresol, 1999) due to the inherent correlations among different components (Dong et al., 2015). To address the additivity of incompatibility, we used seemingly unrelated regression (SUR) and nonlinear seemingly unrelated regression (NSUR) to analyze and estimate the model coefficients, and these methods typically result in a lower variance for the total tree biomass model (Parresol, 1999; Parresol, 2001) because of their generality and flexibility (Li and Zhao, 2013; Dong et al., 2014, 2015; Meng et al., 2017). At the same time, a likelihood analysis has been shown to be a necessary analysis for error structure (Parresol, 2001; Dong et al., 2015). In practice, logarithmic transformation of the power function by using log-transformed data has been frequently and directly used in many studies (Wang, 2006; Zianis et al., 2011). In additive system, each component model can use its own weight function for heteroscedasticity, and additivity is ensured by setting constraints on the regression coefficients (Parresol, 2001; Lambert et al., 2005).

Chinese boreal forests are discontinuously distributed in the high mountains ranges in the middle and western China, including the Altay Mountains (Ni, 2004). The Altay Mountains, located in Central Asia along the border regions of Russia, Mongolia, Kazakhstan, and China, is one of the largest mountain ranges and these mountains play an important role in shaping the climate and ecosystems in Central and North Asia. The Altay Mountain forest in Northwest China 
is not only the extension of southern taiga of west Siberian in the south, but also the characteristic of dark-coniferous boreal forest that extends to the grassland district. Larix species are distributed in boreal forests of the northern hemisphere (Koizumi et al., 2003). Siberian larch (Larix sibirica Ledeb.), which is distributed from Mongolia to the east (Kazakhstan and Siberia) and extends to the dry arid landscapes of China, is a dominant and highly climate-sensitive species (Chytrý et al., 2008; Shuman et al., 2011; Chen et al., 2012). L. sibirica wood comprises $95.68 \%$ of the total stock of the Altay Mountain forests (Huang et al., 2015). In recent years, the Altay Mountains have shown to be the most sensitive and distinct warming districts in terms of global climate change in a half century because of the central Eurasian continental and arid environment (Chen et al., 2012; Zhang et al., 2016). The relationship between L. sibirica tree rings and climate change has been extensively studied (Frank et al., 2007; Dulamsuren et al., 2010; Chen et al., 2012; Dulamsuren et al., 2013; Jiao et al., 2015). However, little research has been conducted in relation to the carbon pool (Dulamsuren et al., 2016). To our knowledge, few equations have been empirically developed to estimate L. sibirica tree biomass in the Chinese Altay Mountains, and the carbon pool of $L$. sibirica forest in the southern boreal region of the Altay Mountains is still poorly understood. Compared to the number of studies carried out in the Mongolian Altay Mountains (Battulga et al., 2013; Dulamsuren et al., 2016), few studies have been conducted in the Chinese Altay Mountains. Therefore, the objectives of this study were to (1) propose equations for estimating stem wood, stem bark, branch, and needle biomass at the individual tree level for L. sibirica, (2) develop simultaneous equations of linear models of biomass based on SUR, and use these models to guarantee the property of additivity, and (3) estimate carbon stock density and carbon storage in the Chinese Altay Mountains.

\section{Materials and methods}

\subsection{Study area}

The study area is the forest regions of the Altay Mountains in Northwest China $\left(44^{\circ} 59^{\prime}-49^{\circ} 10^{\prime} \mathrm{N}\right.$, $85^{\circ} 31^{\prime}-91^{\circ} 01^{\prime} \mathrm{E}$ ), which belongs to the National Forest Bureau of the Altay Mountains in Xinjiang Uygur Autonomous Region. The elevation in the Altay Mountains typically ranges from 1000 to $3000 \mathrm{~m}$ a.s.l. The study area is characterized by a typical cold continental climate. The annual mean temperature is $1.1^{\circ} \mathrm{C}$, while the mean annual precipitation is $362.8 \mathrm{~mm}$. The main arbor tree species in the forest community include L. sibirica, Pinus sibirica, and Abies sibirica. These species are commonly considered as the climax components.

\subsection{Field sampling and measurements}

A total of 51 temporary plots were established in a typical L. sibirica stand in late June 2015 . The circle-shaped plots each had a radius of $9 \mathrm{~m}$, and these plots were selected to record basic individual tree variables. A total of 851 trees were measured, and the diameter distribution tended to be normal (Fig. 1). Table 1 displays the characteristics and descriptive statistics for the basic variables.

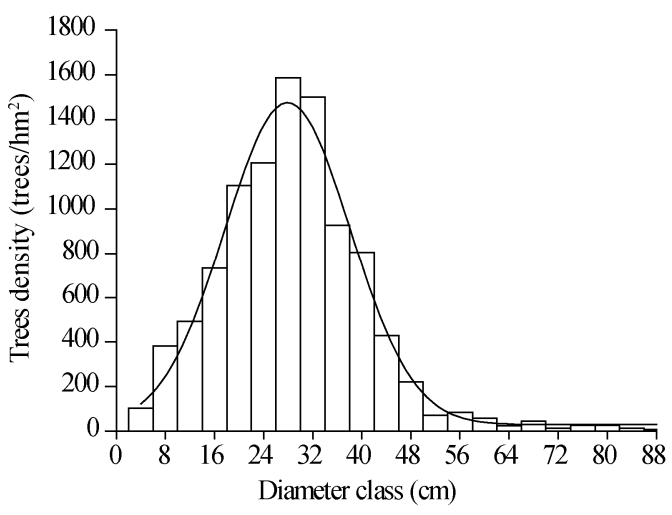

Fig. 1 Diameter distribution of Larix sibirica in the sample plots 
Table 1 Characteristics of Larix sibirica forest

\begin{tabular}{cccccccc}
\hline Forest type & $\begin{array}{c}\text { Mean } \\
\text { DBH }(\mathrm{cm})\end{array}$ & $\begin{array}{c}\text { Mean } \\
\text { height }(\mathrm{m})\end{array}$ & $\begin{array}{c}\text { Basal } \\
\text { area } \\
\left(\mathrm{m}^{2} / \mathrm{hm}^{2}\right)\end{array}$ & $\begin{array}{c}\text { Stand } \\
\text { density } \\
\left(\text { tree } / \mathrm{hm}^{2}\right)\end{array}$ & $\begin{array}{c}\text { Stand } \\
\text { volume } \\
\left(\mathrm{m}^{3} / \mathrm{hm}^{2}\right)\end{array}$ & $\begin{array}{c}\text { Slope } \\
\left({ }^{\circ}\right)\end{array}$ & $\begin{array}{c}\text { Altitude } \\
(\mathrm{m})\end{array}$ \\
\hline L. sibirica & $13.35-77.06$ & $11.67-30.22$ & $2.15-61.81$ & $38-983$ & $20.08-612.46$ & $5-19$ & $1200-2300$ \\
\hline Note: DBH, diameter at breast height.
\end{tabular}

Fallen woods were used to develop aboveground and component biomass equations because destructive sampling is restricted for non-commercial uses in the study area. Thirty fresh and integrated windfall woods were selected for the specific components biomass research. Table 2 lists the descriptive statistics for diameter $(\mathrm{cm})$, height $(\mathrm{m})$, wood/branch density $\left(\mathrm{kg} / \mathrm{m}^{3}\right)$, and aboveground biomass $(\mathrm{kg})$.

Table 2 Summary of individual tree statistics for Larix sibirica

\begin{tabular}{lcrrr}
\hline \multicolumn{1}{c}{ Index } & Minimum & Maximum & Mean & SD \\
\hline Diameter at breast height $(\mathrm{cm})$ & 7.20 & 59.50 & 29.40 & 16.65 \\
Height $(\mathrm{m})$ & 7.62 & 29.74 & 18.36 & 6.78 \\
Stem wood density $\left(\mathrm{kg} / \mathrm{m}^{3}\right)$ & 408.60 & 558.70 & 518.00 & 0.042 \\
Stem bark density $\left(\mathrm{kg} / \mathrm{m}^{3}\right)$ & 475.45 & 410.80 & 433.00 & 0.023 \\
Branch density $\left(\mathrm{kg} / \mathrm{m}^{3}\right)$ & 497.00 & 503.10 & 499.10 & 0.003 \\
Aboveground biomass $(\mathrm{kg})$ & 14.09 & 1822.71 & 536.68 & 582.84 \\
\hline
\end{tabular}

Note: SD, standard deviation.

Different parts of tree biomass can be estimated using the mean density multiplied by the volume of different trees for the same species (Zhang et al., 1998). In this study, we estimated the biomass of the stem and branch using a volume conversion based on density (Table 2). DBH, the diameter of 2-m sections and two terminals and the length of the top section which could not be 2 $\mathrm{m}$, were measured using the fallen woods. Then, the volume of the stem was calculated using Equation 1 (Meng, 2006). Stem bark volume $(V)$ was obtained by subtracting the volume of the inside bark from the volume of the over-bark.

$$
V=\left[\frac{1}{2}\left(r_{0}^{2}+r_{\mathrm{n}}^{2}\right)+\sum_{i=1}^{n-1} r_{i}^{2}\right] \pi l+\frac{1}{3} \pi r_{n}^{2} l^{\prime},
$$

where $r_{0}, r_{i}$ and $r_{n}$ are the radii $(\mathrm{cm})$ of the stem base, large and small of a section, respectively; and, $l$ and $l^{\prime}$ are the section length (m) and the length of top section $(\mathrm{m})$, respectively.

We determined the volume of branches and the quantity of needles based on the nested method (Liu, 2009; Jia et al., 2015; Fig. 2). The diameters of all first-order branches of fallen woods were measured using a digital caliper $( \pm 0.01 \mathrm{~mm})$. A sample unit was selected from the largest first-order branch, and all diameters of the second-order branch were measured; the largest second-order branch was selected to measure all diameters of the third-order branch, and the method was repeated until the last order of branches was reached. The main branch was applied at $50 \mathrm{~cm}$ intervals using a sectional method, and the measured diameter was used to calculate the section volume (Eq. 1). A total of 31 main branches were measured, with diameters ranging from 3.1 to $28.3 \mathrm{~cm}$. Stem wood, stem bark and branches taken from fallen woods were collected to determine tissue density. Water displacement was adopted for volume measurements before the sample was oven-dried at $75^{\circ} \mathrm{C}$ for $48 \mathrm{~h}$ to estimate the dry weight. The basic density and the ratio of dry mass to fresh volume were used to convert the biomass from the volume. The parameters of branch volume with the main branch, the first-order branch, and the individual tree are displayed in Figure 2.

Simultaneously, several first-order branches were integrated, and dense needles were selected to measure the diameter of the main branches and to record the number of leaf fascicles. A total of 41 main branches were measured, with diameters ranging from 0.2 to $1.0 \mathrm{~cm}$. The equation was established to relate the number of leaf fascicles with the diameter of the main branch. Thirty leaf 


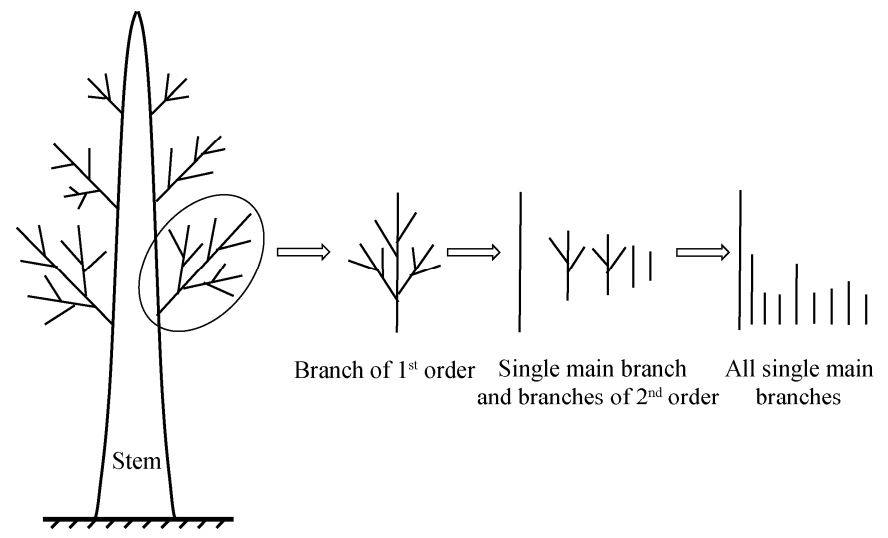

Fig. 2 A diagram showing the dissection of branches into the single main branches

fascicles were randomly selected, the number of needles in every leaf fascicle was counted, and an average value was obtained. Additionally, 220 fresh needles were randomly selected to scan in grayscale at 1200 dpi resolution to calculate the individual leaf area. Needles were dried to a constant mass at $70^{\circ} \mathrm{C}$. The mean dry biomass of needles was calculated. Equation 2 was used to calculate needle biomass. The parameters of the leaf fascicles are shown in Table 3.

$$
W_{\text {needle }}=N_{b} \times(0.0017 \times 36) / 1000 \text {, }
$$

where $W_{\text {needle, }} N_{b}, 0.0017$, and 36 are the needle biomass $(\mathrm{kg})$, number of leaf fascicles, mean needle number of a single leaf fascicle, and dry weight of an individual needle ( $\mathrm{g}$ ), respectively.

Table 3 Parameters of regression equations of needle and branch

\begin{tabular}{lclcccc}
\hline Item & Component & Regression equation & $n$ & $R_{\text {adj }}^{2}$ & $\begin{array}{c}\text { Diameter range } \\
(\mathrm{cm})\end{array}$ & $P$ value \\
\hline \multirow{2}{*}{$\begin{array}{l}\text { Number of } \\
\text { leaf fascicles }\end{array}$} & Main branch & $N_{b}=29.51 \ln X+73.16$ & 41 & 0.73 & $0.19-1.00$ & $<0.001$ \\
& Indivt-order branch & $N_{b}=274.19 X^{1.7911}$ & 285 & 0.71 & $0.05-48.10$ & $<0.001$ \\
& Main branch & $V=0.00005 X^{2.3605}$ & 31 & 0.95 & $3.10-28.30$ & $<0.001$ \\
Branch & First-order branch & $V=0.00005 X^{2.4538}$ & 285 & 0.94 & $0.05-48.10$ & $<0.001$ \\
volume & Individual tree & $V=0.00001 \mathrm{DBH} \mathrm{H}^{2.3433}$ & 30 & 0.93 & $7.20-59.20$ & $<0.001$ \\
\hline
\end{tabular}

\subsection{Allometric equations analysis}

We estimated carbon storage of the Alay Mountains using the carbon concentration rate (0.5) and the carbon density $\left(\mathrm{Mg} \mathrm{C} / \mathrm{hm}^{2}\right)$, which was based on the optimal biomass model, plot data, and forest inventory data in the Altay Mountains. In this study, there were four tree components including stem wood, stem bark, branches, and needles. To satisfy the inherent correlations among the components of tree biomass that were measured on the same sampled trees, we developed the additivity property of biomass equations. Then, we applied a general biomass equation model based on DBH or on both $\mathrm{DBH}$ and $\mathrm{H}$, as unique predictors in Equations 3 and 4.

$$
\begin{gathered}
W=\mathbf{a} \times \mathrm{DBH}^{\mathrm{b}}, \\
W=\mathbf{a} \times \mathrm{DBH}^{\mathrm{b}} \times H^{\mathrm{c}},
\end{gathered}
$$

where $W$ is the biomass $(\mathrm{kg})$; and $\mathrm{a}, \mathrm{b}$, and c are the coefficients.

Because of the heteroscedasticity of the raw data (Parresol, 1999), we defined and used a logarithmic transformation for each biomass model. Fitting was conducted using the Systemfit package for R3.3.1 by the R Core Team, and the coefficients of the tree component biomass models were simultaneously estimated. The figures were constructed using Origin Pro 8.5.0 SR1.

We specified the additive system of the log-transformed equations based on Equation 3 as follows: 


$$
\begin{gathered}
\ln W_{\text {wood }}=\mathrm{a}_{11}+\mathrm{b}_{11} \times \operatorname{lnDBH}+\varepsilon_{\text {wood }}, \\
\ln W_{\text {bark }}=\mathrm{a}_{12}+\mathrm{b}_{12} \times \ln \mathrm{DBH}+\varepsilon_{\text {bark }}, \\
\ln W_{\text {branch }}=\mathrm{a}_{13}+\mathrm{b}_{13} \times \operatorname{lnDBH}+\varepsilon_{\text {branch }}, \\
\ln W_{\text {needle }}=\mathrm{a}_{14}+\mathrm{b}_{14} \times \operatorname{lnDBH}+\varepsilon_{\text {needle }}, \\
\ln W_{\text {crown }}=\ln \left(W_{\text {branch }}+W_{\text {needle }}\right) \\
=\ln \left(\mathrm{a}_{13}^{*} \times \mathrm{DBH}^{b_{13}}+\mathrm{a}_{14}^{*} \times \mathrm{DBH}^{\mathrm{b}_{14}}\right)+\varepsilon_{\text {crown }}, \\
\ln W_{\text {aboveground }}=\ln \left(W_{\text {wood }}+W_{\text {bark }}+W_{\text {branch }}+W_{\text {needle }}\right)+\varepsilon_{\text {aboveground }}, \\
=\ln \left(\mathrm{a}_{11}^{*} \times \mathrm{DBH}^{\mathrm{b}_{11}}+\mathrm{a}_{12}^{*} \times \mathrm{DBH}^{\mathrm{b}_{12}}+\mathrm{a}_{13}^{*} \times \mathrm{DBH}^{\mathrm{b}_{13}}+\mathrm{a}_{14}^{*} \times \mathrm{DBH}^{\mathrm{b}_{14}}\right)+\varepsilon_{\text {aboveground }},
\end{gathered}
$$

We presented the additive system of the log-transformed models based on Equation 4 as follows:

$$
\begin{aligned}
& \ln W_{\text {wood }}=\mathrm{a}_{21}+\mathrm{b}_{21} \times \ln \mathrm{DBH}+\mathrm{c}_{21} \times \ln \mathrm{H}+\varepsilon_{\text {wood }} \text {, } \\
& \ln W_{\text {bark }}=\mathrm{a}_{22}+\mathrm{b}_{22} \times \ln \mathrm{DBH}+\mathrm{c}_{22} \times \ln \mathrm{H}+\varepsilon_{\text {bark }} \text {, } \\
& \ln W_{\text {branch }}=\mathrm{a}_{23}+\mathrm{b}_{23} \times \ln \mathrm{DBH}+\mathrm{c}_{23} \times \ln \mathrm{H}+\varepsilon_{\text {branch }} \text {, } \\
& \ln W_{\text {needle }}=\mathrm{a}_{24}+\mathrm{b}_{24} \times \operatorname{lnDBH}+\mathrm{c}_{24} \times \ln \mathrm{H}+\varepsilon_{\text {needle }}, \\
& \ln W_{\text {crown }}=\ln \left(W_{\text {branch }}+W_{\text {needle }}\right) \text {, } \\
& =\ln \left(\mathrm{a}_{23}^{*} \times \mathrm{DBH}^{\mathrm{b}_{23}} \times \mathrm{H}^{\mathrm{c}_{23}}+\mathrm{a}_{24}^{*} \times \mathrm{DBH}^{\mathrm{b}_{24}} \times \mathrm{H}^{\mathrm{c}_{24}}\right)+\varepsilon_{\text {crown }}, \\
& \ln W_{\text {aboveground }}=\ln \left(W_{\text {wood }}+W_{\text {bark }}+W_{\text {branch }}+W_{\text {needle }}\right)+\varepsilon_{\text {aboveground }} \text {, } \\
& =\ln \left(\mathrm{a}_{21}^{*} \times \mathrm{DBH}^{\mathrm{b}_{21}} \times \mathrm{H}^{\mathrm{c}_{21}}+\mathrm{a}_{22}^{*} \times \mathrm{DBH}^{\mathrm{b}_{22}} \times \mathrm{H}^{\mathrm{c}_{22}}+\mathrm{a}_{23}^{*} \times \mathrm{DBH}^{\mathrm{b}_{23}} \times \mathrm{H}^{\mathrm{c}_{23}}+\mathrm{a}_{24}^{*} \times \mathrm{DBH}^{\mathrm{b}_{24}} \times \mathrm{H}^{\mathrm{c}_{24}}\right)+\varepsilon_{\text {aboveground }} \text {, }
\end{aligned}
$$

where $W_{\text {wood, }} W_{\text {bark }}, W_{\text {branch, }} W_{\text {needle, }}, W_{\text {crown }}$, and $W_{\text {aboveground }}$ represent the stem wood, stem bark, branch, foliage, crown, and aboveground biomass $(\mathrm{kg})$, respectively; $\mathrm{a}_{\mathrm{mn}}, \mathrm{b}_{\mathrm{mn}}$ and $\mathrm{c}_{\mathrm{mn}}$ are the regression coefficients, in which $m$ represents the $m^{\text {th }}$ system, and $n$ represents the $n^{\text {th }}$ biomass component; $\varepsilon_{m}$ is the model error term; and $\mathrm{a}_{\mathrm{mn}}^{*}$ is equal to $\exp \left(\mathrm{a}_{\mathrm{mn}}\right)$.

\subsection{Model assessment and validation}

In this study, two additive systems of the biomass models were fitted to the entire biomass data, and model testing was conducted using the jackknifing test. We employed two goodness-of-fit statistical tests (Eqs. 17 and 18, i.e., root mean squared error (RMSE) and coefficient of determination $\left(R^{2}\right)$ ) to evaluate the performance of each model, while we assessed the biomass model prediction performance using three model validation statistics (Eqs. 19-21, i.e., mean absolute error (MAE), relative mean absolute error $\left(\mathrm{MAE}_{\mathrm{R}}\right)$, and prediction coefficient of determination $\left(R_{\mathrm{p}}^{2}\right)$ ) of jackknifing test as follows:

$$
\begin{gathered}
\mathrm{RMSE}=\sqrt{\frac{\sum_{j=1}^{n}\left(y_{j}-\hat{y}_{j}\right)^{2}}{n-k},} \\
R^{2}=1-\frac{\sum_{j=1}^{n}\left(y_{j}-\hat{y}_{j}\right)^{2}}{\sum_{\mathrm{j}=1}^{n}\left(y_{j}-\bar{y}_{j}\right)^{2}}, \\
\mathrm{MAE}=\frac{\sum_{j=1}^{\mathrm{n}}\left|y_{j}-\hat{y}_{j,-j}\right|}{n},
\end{gathered}
$$




$$
\begin{gathered}
\operatorname{MAE}_{\mathrm{R}}=\frac{\sum_{j=1}^{n}\left|y_{j}-\hat{y}_{j,-j}\right|}{n} \times 100, \\
R_{P}^{2}=1-\frac{\sum_{j=1}^{n}\left(y_{j}-\hat{y}_{j,-j}\right)^{2}}{\sum_{j=1}^{n}\left(y_{j}-\bar{y}_{j,-j}\right)^{2}},
\end{gathered}
$$

where $y_{j}$ is the $j^{\text {th }} \log$-transformed observed biomass value; $y_{j}$ is the $j^{\text {th }}$ log-value predicted by the model; $\bar{y}$ is the mean of the log-transformed observed value; $n$ is the total number of observations used for model fitting; $k$ represents the number of parameters; and $y_{j, j}$ is the $j^{\text {th }}$ log-value predicted by the model fitting with the $n-1$ remaining observations, excluding the $j^{\text {th }}$ observation.

\subsection{Correction factor for antilogarithm transformation}

A systematic bias can occur when converting predicted values that have been calculated by applying linear models to the log-transformed data back to arithmetic units. To minimize this bias, we usually applied a simple correction factor $(\mathrm{CF})$ based on the standard error of the estimate, which is larger than 1, to the final biomass estimation for each regression model as follows:

$$
\mathrm{CF}=\exp \left(\mathrm{RMSE}^{2} / 2\right) \text {. }
$$

To assess the effect of the $\mathrm{CF}$, we calculated percent bias $(B)$ as follows:

$$
B=\left(\frac{\mathrm{CF}-1}{\mathrm{CF}}\right) \times 100 \% \text {. }
$$

\section{Results}

\subsection{Model development}

The estimated coefficients, their standard errors of the DBH-based additive system equations and the DBH- and H-based additive system equations are presented in Table 4. The results were always significant at the 0.001 level. For needles, the goodness-of-fit $\left(R^{2}\right)$ was lower than that of all other components. For both equations, the DBH coefficients were always positive for all biomass models. This clearly indicated an increase in all biomass components with an increase in DBH. However, the coefficients of the DBH- and H-based system equations were not always positive, especially for the coefficient c. Except for the needle models, the biomass components performed well, with $R^{2}$ values ranging from 0.926 to 0.995 and $\mathrm{RMSE}<0.357 \mathrm{~kg}$ for the two model forms; in contrast, the needles resulted poor in fitness $\left(R^{2}\right.$ ranging from 0.696 to 0.756 and RMSE ranging from 0.560 to $0.636 \mathrm{~kg}$ ). The stem wood, stem bark, and branch equations that used both DBH and $\mathrm{H}$ produced a better model fit $\left(R^{2}>0.931\right.$ and $\left.\mathrm{RMSE}<0.332 \mathrm{~kg}\right)$ than the models that used only DBH as the predictor, while the needles model showed adverse effects. However, there was no significant difference between crown and aboveground models. DBH was essential for predicting the crown biomass components, while $\mathrm{H}$ was much less useful for the prediction of the crown biomass components.

In this study, CF and its effect were calculated (Table 4). The results revealed that a small variation could arise from the log-transformation of both model forms, regardless of the biomass components. And this result was especially obvious for the stem wood and aboveground biomass equations $(\mathrm{CF}<1.018)$. However, for the separate components (e.g., branches, needles and crown), the $\mathrm{CF}$ showed relatively higher values $(\mathrm{CF}<1.224)$ than those for other individuals or aggregated biomass components. Meanwhile, the percent bias (B) displayed a slightly wider range, i.e., from $0.864 \%$ to $18.295 \%$, and those of the branch, needle and crown were slightly larger (i.e., from $5.375 \%$ to $18.295 \%$ ), with the needle biomass being the largest (i.e., from $14.502 \%$ to $18.295 \%$ ). 
Table 4 Statistics and estimates of $\mathrm{a}, \mathrm{b}$ and $\mathrm{c}$ for the additive system of the log-transformed models reported in Equations 5 and 6

\begin{tabular}{ccccccccc}
\hline Component & Model & $\mathrm{a}$ & $\mathrm{b}$ & $\mathrm{c}$ & $\mathrm{RMSE}$ & $R^{2}$ & $\mathrm{CF}$ & $B(\%)$ \\
\hline \multirow{2}{*}{ Stem wood } & $\mathrm{DBH}$ & $-2.774 \pm 0.142$ & $2.389 \pm 0.044$ & - & 0.192 & 0.984 & 1.018 & 1.830 \\
& $\mathrm{DBH} \& \mathrm{H}$ & $-3.178 \pm 0.172$ & $2.058 \pm 0.103$ & $0.515 \pm 0.150$ & 0.177 & 0.997 & 1.016 & 1.566 \\
\multirow{3}{*}{ Stem bark } & DBH & $-3.352 \pm 0.167$ & $2.466 \pm 0.051$ & - & 0.213 & 0.983 & 1.023 & 2.249 \\
& DBH\&H & $-3.942 \pm 0.241$ & $2.202 \pm 0.135$ & $0.440 \pm 0.203$ & 0.205 & 0.985 & 1.021 & 2.086 \\
Branches & DBH & $-2.295 \pm 0.205$ & $1.752 \pm 0.060$ & - & 0.338 & 0.926 & 1.059 & 5.568 \\
& DBH\&H & $-1.341 \pm 0.266$ & $2.418 \pm 0.114$ & $-1.083 \pm 0.197$ & 0.332 & 0.931 & 1.057 & 5.375 \\
Needles & DBH & $-4.189 \pm 0.431$ & $1.596 \pm 0.131$ & - & 0.560 & 0.756 & 1.169 & 14.502 \\
& DBH\&H & $-1.936 \pm 0.633$ & $3.237 \pm 0.246$ & $-2.687 \pm 0.388$ & 0.636 & 0.696 & 1.224 & 18.295 \\
Crown & DBH & - & - & - & 0.348 & 0.926 & 1.062 & 5.872 \\
& DBH\&H & - & - & - & 0.357 & 0.928 & 1.066 & 6.171 \\
Aboveground & DBH & - & - & - & 0.132 & 0.994 & 1.009 & 0.864 \\
& DBH\&H & - & - & - & 0.134 & 0.995 & 1.009 & 0.898 \\
\hline
\end{tabular}

Note: DBH, diameter at breast height; $\mathrm{H}$, height; $\mathrm{a}, \mathrm{b}$, and c represent the coefficients; RMSE, root mean squared error; $R^{2}$, coefficient of determination; $\mathrm{CF}$, correction factor; $B$, bias. Mean \pm SE. -, no value.

\subsection{Biomass equations performance assessment}

We used the jackknifing test to assess the validity of the log-transformed additive models based on two types of variables. The model validation statistics were computed and are presented in Table 5. The stem wood and aboveground biomass models of the two systems produced relatively small prediction errors $\left(\mathrm{MAE}<0.166\right.$ and $\left.\mathrm{MAE}_{\mathrm{R}}<5 \%\right)$ and had high accuracies $\left(R_{\mathrm{p}}^{2}>0.98\right)$. However, the needle biomass equations performed the worst (MAE ranging from 0.476 to 0.598 and $\mathrm{MAE}_{\mathrm{R}}$ ranging from $17.961 \%$ to $50.515 \%$ ). Based on the DBH\&H model, the aboveground, stem wood and stem bark biomass equations produced much smaller prediction errors than the other biomass equations (e.g., branch, needle, and crown). Moreover, this increased the relative errors and lowered the accuracy compared to the equations where DBH was the only predictor variable.

Table 5 Validation statistics of log-transformed biomass equations using the jackknifing test

\begin{tabular}{|c|c|c|c|c|c|c|}
\hline \multirow{2}{*}{ Component } & \multicolumn{3}{|c|}{$\mathrm{DBH}$} & \multicolumn{3}{|c|}{ DBH\&H } \\
\hline & MAE & $\mathrm{MAE}_{\mathrm{R}}(\%)$ & $R_{\mathrm{p}}^{2}$ & MAE & $\mathrm{MAE}_{\mathrm{R}}(\%)$ & $R_{\mathrm{p}}^{2}$ \\
\hline Stem wood & 0.166 & 4.243 & 0.981 & 0.161 & 4.165 & 0.984 \\
\hline Stem bark & 0.174 & 5.297 & 0.981 & 0.157 & 4.664 & 0.982 \\
\hline Branches & 0.276 & 11.203 & 0.914 & 0.277 & 11.268 & 0.910 \\
\hline Needles & 0.476 & 17.961 & 0.731 & 0.598 & 50.515 & 0.602 \\
\hline Crown & 0.271 & 10.553 & 0.914 & 0.285 & 11.000 & 0.903 \\
\hline Aboveground & 0.109 & 2.160 & 0.992 & 0.102 & 2.042 & 0.994 \\
\hline
\end{tabular}

Note: $\mathrm{DBH}$, diameter at breast height; $\mathrm{H}$, height; MAE, mean absolute error; $\mathrm{MAE}_{\mathrm{R}}$, relative mean absolute error; $R_{\mathrm{p}}^{2}$, prediction coefficient of determination.

\subsection{Aboveground biomass partitioning}

The allocation of aboveground biomass including stem wood, bark, branch, and leaf biomass across the 4-cm DBH class is shown in Figure 3. The biomass distribution patterns of aboveground components of L. sibirica were compatible with the general patterns found for many other tree species. Specifically, the average partitioning was $59.56 \%$ for stem wood, $27.82 \%$ for stem bark, $11.37 \%$ for branch, and $1.25 \%$ for needle. The average proportions of stem woods increased from $50.09 \%$ for small-diameter trees to $69.22 \%$ for large-diameter trees and from $17.00 \%$ to $32.00 \%$ for bark. The average proportions of branches decreased from $29.54 \%$ for small-diameter trees to $5.41 \%$ for large-diameter trees and from $3.18 \%$ to $0.65 \%$ for needle. 


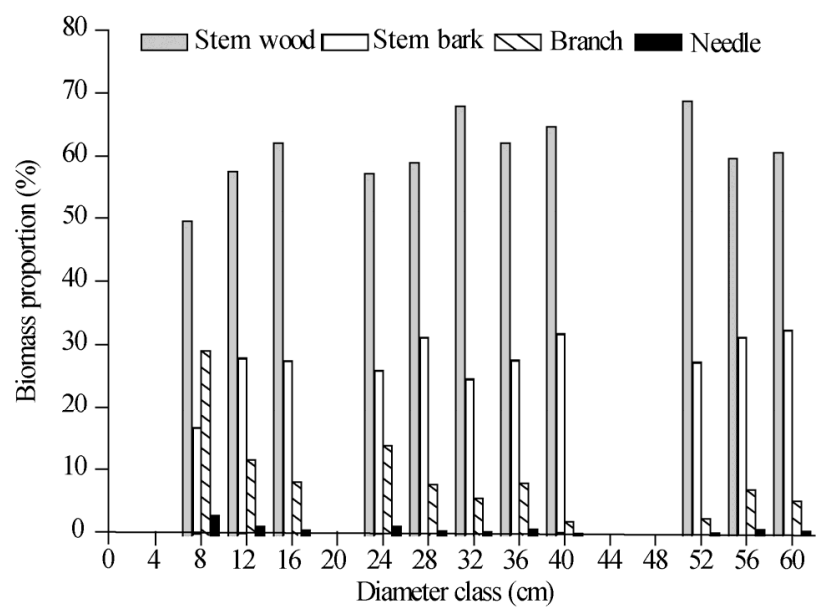

Fig. 3 Proportions of aboveground biomass allocating to stem wood, stem bark, branch, and needle

\subsection{L. sibirica carbon storage}

Based on the SUR method, our biomass models could provide proper estimations, which guarantee additivity among the individual components of $L$. sibirica. Considering the issues described above, the additive system of biomass equations that used DBH as a single predictor can be used to estimate the biomass of either the individual trees or the specific components in this study. The total aboveground biomass was expressed as the sum of the biomasses of the respective tree components (e.g., stem wood, stem bark, branch, and needle). Consequently, based on the additive biomass equations, the mean aboveground biomass estimated for L. sibirica was $148.14 \mathrm{Mg} / \mathrm{hm}^{2}$. The average carbon density was $74.07 \mathrm{Mg} \mathrm{C} / \mathrm{hm}^{2}$ in the Altay Mountains, and the carbon storage was estimated to $30.69 \mathrm{Tg} \mathrm{C}$.

\section{Discussion}

\subsection{Model availability}

A graphical comparison of the aboveground and separate component equations illustrated the differences between our models and the biomass equations of Battulga et al. (2013) for L. sibirica (Fig. 4). Apparently, there was a subtle divergence from our established values for aboveground biomass, especially for large trees (Fig. 4a). Many studies have indicated that site condition, e.g., forest types, stand ages, soil conditions and forest densities, contributes significantly to the variation in the aboveground biomass (Zhou et al., 2002; Li et al., 2006; Alvarez et al., 2012; Dong et al., 2015). Thus, using these equations at a specific site can result in biased estimates of biomass and carbon (Cairns et al., 2003), and the applicability of generalized models to new sites must be tested prior to application (Hall et al., 2002; Youkhana and Idol, 2011; Li and Zhao, 2013). The forest in the Chinese Altay Mountains represents the southernmost limit of the taiga forests. The regional climate of the mountains is mainly controlled by the westerlies that are affected by the distant oceans (Zhang et al., 2016), and trees that were affected by drought on south-facing slopes were excluded because precipitation decreased from north to south. Mature and over-mature stands occupied large proportions of the Altay Mountains (Huang et al., 2015). In this study, our stem equation produced higher predictions (Fig. 4b), while under-predicted values were obtained for branches and needles (Figs. 4a, c and d). This result was probably attributed to the higher wood density and lower precipitation under the ultra-continental climate of Mongolia compared to that in the Chinese Altay Mountains.

At the same time, it should be noted that the application of the models must be within a certain diameter range (Anitha et al., 2015), which is often neglected in practice. Many studies did not point out the diameter range that was sampled, or the studies used a limited range in diameter (Anitha et al., 2015). Picard et al. (2012) have suggested that it is difficult to choose 

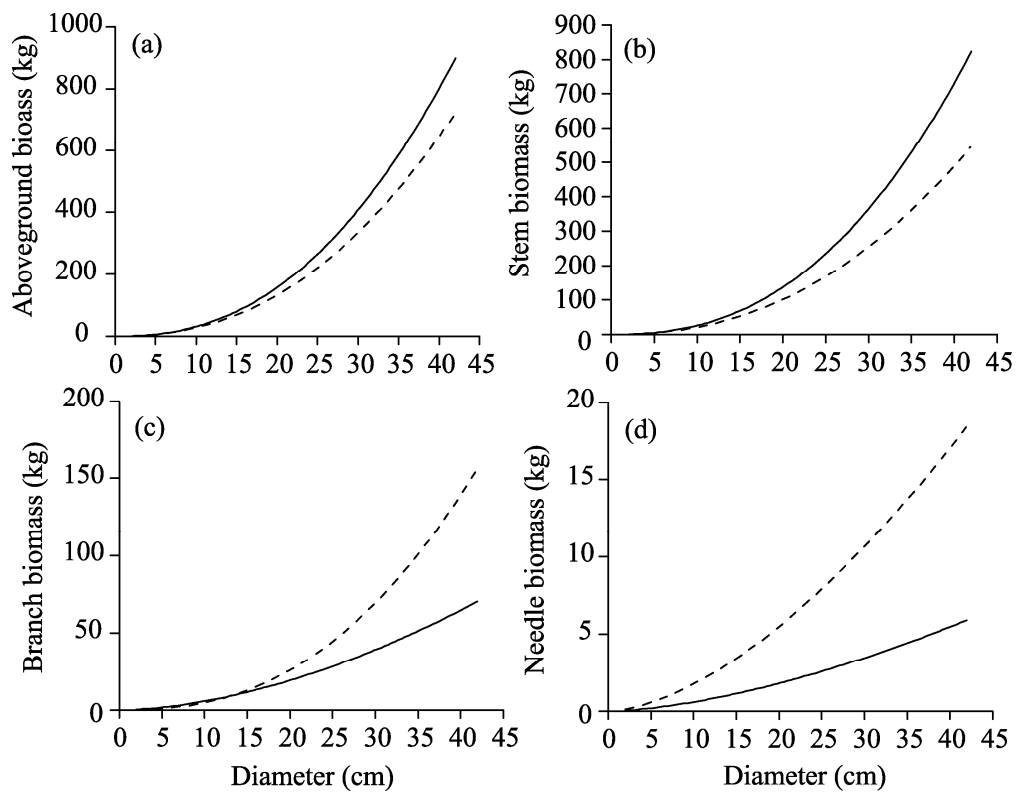

Fig. 4 Model predictions of aboveground (a) and separate component (stem, branch and needle biomass; b-d) equations (solid line) for the Chinese Altay Mountains (this study) compared to the published equations (dashed line) for the Mongolian Altay Mountains (Battulga et al., 2013)

species-specific biomass equations for focal species because most published biomass equations are site-specific estimations that were developed using sample trees at each study site. While comparing our own results with those of other authors, one thing should be considered: in some cases, we should extrapolate the other models beyond the original range of data (Annighöfer et al., 2012). In this study, we have extrapolated the published range of equations $(6 \mathrm{~cm}<\mathrm{DBH}<22 \mathrm{~cm})$. Meanwhile, the low number of samples available also affects the regression coefficient of the equation (Blujdea et al., 2012). It is well known that accurately estimating the biomass of large trees is critical to the process of estimating the stand biomass because large trees usually account for a greater proportion of biomass in a stand (Gower et al., 1999). Thus, if our biomass equations were used to estimate biomass outside of the data range $(\mathrm{DBH}<7 \mathrm{~cm}$ or $\mathrm{DBH}>60 \mathrm{~cm})$, the models might produce large prediction errors.

\subsection{Effect of seed equation on biomass model accuracy}

In this study, the branches and needles of individual trees were estimated by the nested regression method. The regression model for the main branches is called the seed equation and should have good reliability to decrease propagation error (Liu, 2009; Jia et al., 2015). The determination coefficient of the leaf seed equation was 0.73 (Table 3). As expected, the equations could not adequately predict the biomass of needles, due to the environmental and local conditions that affect this component (Blujdea et al., 2012), e.g., forest types, the number of sampled trees and the range of tree sizes. Our equation underestimated the needle biomass compared to the values reported in the literature (Fig. 4d), which is consistent with the results of a previous report (Wang, 2006), probably because leaf is very sensitive to water and soil conditions (Bondlamberty et al., 2002; Wang et al., 2005). Thus, it is better to estimate these biomasses by using site-specific equations (Gower et al., 1999). Moreover, the coefficient of determination of the branch seed equation was higher $\left(R^{2}=0.95\right.$; Table 3$)$ than that of previous result. Our branch equation predicted lower biomass than did the comparative literature when diameter was above $15 \mathrm{~cm}$ (Fig. 4c). Simultaneously, the related study has shown that stem biomass increased with large diameter classes and tree ages of $L$. sibirica, while the branch and needle biomasses decreased (Zhang et al., 2017). Researchers must consider that the variance in crown biomass estimations is higher than that obtained from stem biomass estimations (Carvalho and Parresol, 2003). As we know, the workload involved with collecting branches and needles is laborious and time-consuming in the 
field. Although some predictive differences were found between our models and other published studies, compared to direct weighing, the nested regression method was appropriate to establish branch and needle biomass equations, and this was fast and time-saving method.

\subsection{Correction for log-transformed models}

The CF is a simple and straightforward way to remove systematic bias that is introduced by anti-log transformation of the obtained biomass at the original scale when fitting log-transformed biomass models (Sprugel, 1983). However, this anti-log transformation process leads to a systematic underestimation of the expected biomass (Dong et al., 2015). In this study, the CF values of all biomass equations were less than 1.224, especially for the aboveground, and the stem biomass equations $(<1.018$ ). The percent bias (B) ranged from $0.864 \%$ to $18.295 \%$ (Table 3 ), and the $\mathrm{B}$ value for the needle biomass was the largest $(8.295 \%-14.502 \%)$ and was slightly larger than those calculated in other studies (Zianis et al., 2011; Dong et al., 2014; Meng et al., 2017), where the anti-log correction was ignored. Thus, we should give this topic more consideration in the future.

\subsection{Selection of allometric regression functions}

In practice, the use of $\mathrm{DBH}$ as the only explanatory variable leads to good results and might be sufficient for calculations, especially for individuals originating from the same site (Annighöfer et al., 2012). The DBH\&H combined equations could improve the DBH-only equations (Table 5), which was consistent with the results from previous studies (Bi et al., 2004; Wang, 2006; Zhou et al., 2007; Li and Zhao, 2013). However, there was a $<2 \%$ increase in $R^{2}$ (Table 5) after the incorporation of $\mathrm{H}$ and $\mathrm{DBH}$ in this study. As we know, obtaining $\mathrm{H}$ is costly in terms of labor and time, and $\mathrm{H}$ is difficult to be accurately measured (Wirth et al., 2004; Zianis et al., 2005). Therefore, the existing allometric equations had large differences and were difficult to be selected (Zhang and Wang, 2008). Several studies have concluded that $\mathrm{H}$, as an additional predictor, only adds marginal precision to the predictive ability of DBH-based biomass regressions (Wang, 2006; Anitha et al., 2015; Dong et al., 2015; Meng et al., 2017). The coefficient estimation of system equations (Table 4) that use only DBH has revealed that the coefficient $b$ for DBH is always positive, which indicated that the biomass of all components increased with DBH. However, it was observed that the coefficient $\mathrm{c}$ for $\mathrm{H}$ in the models based on $\mathrm{DBH}$ and $\mathrm{H}$ was positive for stem and bark biomasses, and the coefficient $c$ was negative for branch and foliage biomasses, which is in agreement with previous reports (Lambert et al., 2005; Meng et al., 2017). This means that a taller tree has fewer branches and less foliage even if the DBH value is the same (Hosoda and Iehara, 2010). Therefore, for the models that use an additional explanatory variable with $\mathrm{DBH}$, their performance is mainly dependent on the value that is being estimated (Annighöfer et al., 2012; Menéndezmiguélez et al., 2013). Therefore, we suggested that DBH-only equations should be used to estimate the stand biomass.

\subsection{Intra- and inter-differences in aboveground biomass and carbon stock density}

There is a considerable spatial variation in carbon stock densities, due to tree species composition, climate, soils, and land-use history (Dulamsuren et al., 2016). Dulamsuren et al. (2016) conducted aboveground biomass estimates for L. sibirica, and the values ranged from 109 to $146 \mathrm{Mg} / \mathrm{hm}^{2}$; additionally, carbon stock density in the aboveground biomass of mature forests had an average of $68.4( \pm 6.9) \mathrm{Mg} \mathrm{C} / \mathrm{hm}^{2}$ in the Mongolian Altay Mountains. In this study, the mean aboveground biomass and carbon stock density were $148.14 \mathrm{Mg} / \mathrm{hm}^{2}$ and $74.07 \mathrm{Mg} \mathrm{C} / \mathrm{hm}^{2}$, respectively. The mean aboveground carbon stock density estimated for L. sibirica forest in both the Chinese and the Mongolian Altay mountains was in the upper range of carbon stock densities known for boreal forests (Thurner et al., 2014). This result might be related to long growing season and action of drought stress, which result in a lower stand turnover rate and thus a higher standing biomass (Jarvis and Linder, 2000; Dulamsuren et al., 2016). At the location of our study at the southernmost distribution limit of taiga forests, there would be a higher stand biomass than that found in other boreal forests. Ni (2004) indicated that the mountain-based forest net primary productivity (NPP) was approximately $0.9 \mathrm{Mg} /\left(\mathrm{hm}^{2} \cdot \mathrm{a}\right)$ in the Chinese Altay Mountains. 
Dulamsuren et al. (2013) demonstrated that growth declines in Siberian boreal forest were caused by a decrease in the effective moisture due to the increase in summer temperatures caused by climate warming in the southernmost $L$. sibirica forests of eastern Kazakhstan. On the other hand, the aboveground carbon stock density was much higher than that in the L. gmelinii stand (total biomass ranged from 8.6 to $33.1 \mathrm{Mg} / \mathrm{hm}^{2}$ with stand-level $\mathrm{T} / \mathrm{R}$ (i.e., aboveground-total/root biomass ranging from 1.5 to 2.6) (Kajimoto et al., 2006), and NPP was estimated to be 1.8 $\mathrm{Mg} /\left(\mathrm{hm}^{2} \cdot \mathrm{a}\right)$ with permafrost soils in central Siberia (Kajimoto et al., 1999). As we know, $L$. gmelinii is also an important species in the forest ecosystems of northeastern China. Wang et al. (2005) concluded that natural $L$. gmelinii forests exhibited a decreased NPP when the biomass was higher than $100-110 \mathrm{Mg} / \mathrm{hm}^{2}$, and when the aboveground biomass and NPP for mature $L$. gmelinii forests were $42.93-190.25 \mathrm{Mg} / \mathrm{hm}^{2}$ and $1.1-4.0 \mathrm{Mg} /\left(\mathrm{hm}^{2} \cdot \mathrm{a}\right)$, respectively, at the stand level in the Da Hinggan Ling Mountains, China.

\section{Conclusions}

Allometric models with measured variables are simple to use in forest carbon estimation for their time-saving and cost effective characteristics. Two additive systems of biomass equations were developed, and the equations obtained in this study provided an operational method for accurately estimating the aboveground biomass of individual natural L. sibirica trees, which are widely distributed in the Altay Mountains, China. Finally, additive equations that used DBH as the single predictor were intended to be used to estimate carbon sequestration. Because cutting or harvesting trees is strictly prohibited in natural forest, carbon accounting can be conducted using the developed models that rely on non-destructive methods. The availability of different component biomass estimates can also provide references for the formulating of conservation strategies.

\section{Acknowledgements}

This study was financially supported by the National High-Tech Research and Development Plan of China (2013AA122003). The authors would like to thank the local forestry bureaus for their kind assistance during the investigation. Thanks to Nurjan HABYDEN for valuable support on fieldwork. Thanks also to anonymous reviewers who gave us valuable suggestions.

\section{References}

Alvarez E, Duque A, Saldarriaga J, et al. 2012. Tree above-ground biomass allometries for carbon stocks estimation in the natural forests of Colombia. Forest Ecology and Management, 267(297): 297-308.

Anitha K, Verchot L V, Joseph S, et al. 2015. A review of forest and tree plantation biomass equations in Indonesia. Annals of Forest Science, 72(8): 981-997.

Annighöfer P, Mölder I, Zerbe S, et al. 2012. Biomass functions for the two alien tree species Prunus serotina Ehrh. and Robinia pseudoacacia L. in floodplain forests of Northern Italy. European Journal of Forest Research, 131(5): 1619-1635.

Basuki T M, van Laake P E, Skidmore A K, et al. 2009. Allometric equations for estimating the above-ground biomass in tropical lowland dipterocarp forests. Forest Ecology and Management, 257(8): 1684-1694.

Battulga P, Tsogtbaatar J, Dulamsuren C, et al. 2013. Equations for estimating the above-ground biomass of Larix sibirica in the forest-steppe of Mongolia. Journal of Forestry Research, 24(3): 431-437.

Bi H, Turner J, Lambert M J. 2004. Additive biomass equations for native eucalypt forest trees of temperate Australia. Trees, 18(4): 467-479.

Blujdea V N B, Pilli R, Dutca I, et al. 2012. Allometric biomass equations for young broadleaved trees in plantations in Romania. Forest Ecology and Management, 264(1): 172-184.

Bonan G B. 2008. Forests and climate change: forcings, feedbacks, and the climate benefits of forest. Science, 320(5882): $1444-1449$

Bond-Lamberty B, Wang C, Gower S T. 2002. Aboveground and belowground biomass and sapwood area allometric equations for six boreal tree species of northern Manitoba. Canadian Journal of Forest Research, 32(8): 1441-1450.

Cairns M A, Haggerty P K, Alvarez R, et al. 2000. Tropical Mexico's recent land-use change: A region's contribution to the global carbon cycle. Ecological Applications, 10(5): 1426-1441. 
Cairns M A, Olmsted I, Granados J, et al. 2003. Composition and aboveground tree biomass of a dry semi-evergreen forest on Mexico's Yucatan Peninsula. Forest Ecology and Management, 186(1-3): 125-132.

Carvalho J P, Parresol B R. 2003. Additivity in tree biomass components of Pyrenean oak (Quercus pyrenaica Willd.). Forest Ecology and Management, 179(1-3): 269-276.

Chauchard S, Beilhe F, Denis N, et al. 2010. An increase in the upper tree-limit of silver fir (Abies alba Mill.) in the Alps since the mid-20 $0^{\text {th }}$ century: A land-use change phenomenon. Forest Ecology and Management, 259(8): 1406-1415.

Chen F, Yuan Y J, Wei W S, et al. 2012. Climatic response of ring width and maximum latewood density of Larix sibirica in the Altay Mountains, reveals recent warming trends. Annals of Forest Science, 69(6): 723-733.

Chytrý M, Danihelka J, Kubešová S, et al. 2008. Diversity of forest vegetation across a strong gradient of climatic continentality: Western Sayan Mountains, southern Siberia. Plant Ecology, 196(1): 61-83.

Dong L, Zhang L, Li F. 2014. A compatible system of biomass equations for three conifer species in Northeast, China. Forest Ecology and Management, 329: 306-317.

Dong L, Zhang L, Li F. 2015. Developing additive systems of biomass equations for nine hardwood species in Northeast China. Trees, 29(4): 1149-1163.

Dulamsuren C, Hauck M, Khishigjargal M, et al. 2010. Diverging climate trends in Mongolian taiga forests influence growth and regeneration of Larix sibirica. Oecologia, 163(4): 1091-1102.

Dulamsuren C, Wommelsdorf T, Zhao F, et al. 2013. Increased summer temperatures reduce the growth and regeneration of Larix sibirica in southern boreal forests of eastern Kazakhstan. Ecosystems, 16(8): 1536-1549.

Dulamsuren C, Klinge M, Degener J, et al. 2016. Carbon pool densities and a first estimate of the total carbon pool in the Mongolian forest-steppe. Global Change Biology, 22(2): 830-844.

Fang J, Chen A, Peng C, et al. 2001. Changes in forest biomass carbon storage in China between 1949 and 1998. Science, 292(5525): 2320-2322.

Frank D, Ovchinnikov D, Kirdyanov A, et al. 2007. The potential for long-term climatic reconstructions in the central Altay Mountains from living and relict larch. Trace, 5: 85-96.

Gower S, Kucharik C, Norman J. 2007. Direct and indirect estimation of leaf area index. International Journal of Remote Sensing, 5: 259-274.

Goetz S J, Baccini A, Laporte N T, et al. 2009. Mapping and monitoring carbon stocks with satellite observations: a comparison of methods. Carbon Balance and Management, 4(2): 1-7.

Gower S T, Kucharik C J, Norman J M. 1999. Direct and indirect estimation of leaf area index, fAPAR, and net primary production of terrestrial ecosystems. Remote Sensing of Environment, 70(1): 29-51.

Hall R J, Case B S, Arsenault E, et al. 2002. Modeling and mapping forest biomass using forest inventory and Landsat TM data: results from the foothills model forest, Alberta. Geoscience and Remote Sensing Symposium, 2002. IGARSS'02. 2002 IEEE International, 3: 24-28.

Hall R J, Skakun R S, Arsenault E J, et al. 2006. Modeling forest stand structure attributes using Landsat ETM+ data: Application to mapping of aboveground biomass and stand volume. Forest Ecology and Management, 225(1): 378-390.

Hosoda K, Iehara T. 2010. Aboveground biomass equations for individual trees of Cryptomeria japonica, Chamaecyparis obtusa and Larix kaempferi in Japan. Journal of Forest Research, 15(5): 299-306.

Huang L, Gao Y, Li Y, et al. 2015. Growth of siberia larch in the middle east of Altay Mountains and its reponse to climate change. Arid Land Geography, 38(6): 1169-1178. (in Chinese)

Jarvis P, Linder S, Vaganov E A, et al. 2000. Constraints to growth of boreal forests. Nature, 405(6789): 904-905.

Jia Q, Liu Q, Li J. 2015. Individual-based fine root biomass and its functional relationship with leaf for Pinus tabuliformis in northern China. European Journal of Forest Research, 134(4): 705-714.

Jiao L, Jiang Y, Zhang W T, et al. 2015. Divergent responses to climate factors in the radial growth of Larix sibirica in the eastern Tianshan Mountains, northwest China. Trees, 29(6): 1673-1686.

Kajimoto T, Matsuura Y, Sofronov M A, et al. 1999. Above- and below-ground biomass and net primary productivity of a Larix gmelinii stand near Tura, central Siberia. Tree Physiology, 19(12): 815-822.

Kajimoto T, Matsuura Y, Osawa A, et al. 2006. Size-mass allometry and biomass allocation of two larch species growing on the continuous permafrost region in Siberia. Forest Ecology and Management, 222(1-3): 314-325.

Ketterings Q M, Coe R, Van Noordwijk M, et al. 2001. Reducing uncertainty in the use of allometric biomass equations for predicting above-ground tree biomass in mixed secondary forests. Forest Ecology and Management, 146(1-3): 199-209.

Koizumi A, Takata K, Yamashita K, et al. 2003. Anatomical characteristics properties of Larix sibirica grown in south-central Siberia. IAWA Journal, 24(4): 355-370. 
Kuyah S, Sileshi G W, Rosenstock T S. 2016. Allometric models based on Bayesian frameworks give better estimates of aboveground biomass in the miombo woodlands. Forests, 7(2): 1-13.

Lambert M C, Ung C H, Raulier F. 2005. Canadian national tree aboveground biomass equations. Canadian Journal of Forest Research, 35(8): 1996-2018.

Li H, Zhao P. 2013. Improving the accuracy of tree-level aboveground biomass equations with height classification at a large regional scale. Forest Ecology and Management, 289(289): 153-163.

Li X, Liu Q, Hu L, et al. 2006. Calculation of Pinus elliotii biomass: A comparison of different methods. Chinese Journal of Ecology, 25(12):1594-1598. (in Chinese)

Liu Q. 2009. Nested regression for establishing tree biomass equations. Chinese Journal of Plant Ecology, 33(2): 331-337. (in Chinese)

Menéndezmiguélez M, Canga E, Barrio-Anta M, et al. 2013. A three level system for estimating the biomass of Castanea sativa Mill. coppice stands in north-west Spain. Forest Ecology and Management, 291(2): 417-426.

Meng S, Liu Q, Zhou G, et al. 2017. Aboveground tree additive biomass equations for two dominant deciduous tree species in Daxing'anling, northernmost China. Journal of Forest Research, 1-8.

Meng X. 2006. Forest Mensuration ( ${ }^{\text {rd }}$ ed.). Beijing: Chinese Forestry Publishing House, 25-26. (in Chinese)

Ni J. 2004. Forest productivity of the Altay and Tianshan Mountains in the dryland, northwestern China. Forest Ecology and Management, 202(1-3): 13-22.

Pan Y, Birdsey R A, Fang J, et al. 2011. A large and persistent carbon sink in the World's forests. Science, 333(6045): 988-993.

Parresol B R. 1999. Assessing tree and stand biomass: a review with examples and critical comparisons. Forest Science, 45(4): 573-593.

Parresol B R. 2001. Additivity of nonlinear biomass equations. Canadian Journal of Forest Research, 31(5): 865-878.

Pérez-Cruzado C, Rodríguez-Soalleiro R. 2011. Improvement in accuracy of aboveground biomass estimation in Eucalyptus nitens plantations: Effect of bole sampling intensity and explanatory variables. Forest Ecology and Management, 261(11): 2016-2028.

Picard N, Henry M, Mortier F, et al. 2012. Using Bayesian model averaging to predict tree aboveground biomass in tropical moist forests. Forest Science, 58(1): 15-23.

Riofrío J, Herrero C, Grijalva J, et al. 2015. Aboveground tree additive biomass models in Ecuadorian highland agroforestry systems. Biomass and Bioenergy, 80: 252-259.

Shuman J K, Shugart H H, O'Halloran T L. 2011. Sensitivity of Siberian larch forests to climate change. Global Change Biology, 17(7): 2370-2384.

Son Y, Hwang J W, Kim Z S, et al. 2001. Allometry and biomass of Korean pine (Pinus koraiensis) in central Korea. Bioresource Technology, 78(3): 251-255.

Sprugel D G. 1983. Correcting for bias in log-transformed Allometric Equations. Ecology, 64(1): 209-210.

Tei S, Sugimoto A, Yonenobu H, et al. 2014. Growth and physiological responses of larch trees to climate changes deduced from tree-ring widths and $\delta^{13} \mathrm{C}$ at two forest sites in eastern Siberia. Polar Science, 8(2): 183-195.

Thurner M, Beer C, Santoro M, et al. 2014. Carbon stock and density of northern boreal and temperate forests. Global Ecology and Biogeography, 23(3): 297-310.

Tsogt K, Lin C. 2014. A flexible modeling of irregular diameter structure for the volume estimation of forest stands. Journal of Forest Research, 19(1): 1-11.

Wang C, 2006. Biomass allometric equations for 10 co-occurring tree species in Chinese temperate forests. Forest Ecology and Management, 222(1): 9-16.

Wang W, Zu Y, Wang H, et al. 2005. Plant biomass and productivity of Larix gmelinii forest ecosystems in Northeast China: intra- and inter-species comparison. Eurasian Journal of Forest Research-Hokkaido University (Japan), 8(1): 21-41.

Wirth C, Schumacher J, Schulze E D. 2004. Generic biomass functions for Norway spruce in Central Europe-a meta-analysis approach toward prediction and uncertainty estimation. Tree Physiology, 24(2): 121-139.

Xu Y, Zhang J, Franklin S B,et al. 2016. Improving allometry models to estimate the above- and below-ground biomass of subtropical forest, China. Ecosphere, 6(12): 1-15.

Youkhana A H, Idol T W. 2011. Allometric models for predicting above- and below-ground biomass of Leucaena-KX2 in a shaded coffee agroecosystem in Hawaii. Agroforestry Systems, 83(3): 331-345.

Zhang H, Tang S, Xu H. 1998. Studies on the estimate method for average stem density. Forest Research, 11(1): 58-62. (in Chinese) 
Zhang H, Zhu Y, Dixiati B, et al. 2017. Biomass allocation patterns of Picea obovata and Larix sibirica in the Altai Mountains forest area. Journal of Nanjing Forestry University: Natural Sciences Edition, 41(1): 203-208. (in Chinese)

Zhang M, Wang G. 2008. The forest biomass dynamics of Zhejiang Province. Acta Ecologica Sinica, 28(11): 5665-5674. (in Chinese)

Zhang Y, Meyers P A, Liu X, et al. 2016. Holocene climate changes in the central Asia mountain region inferred from a peat sequence from the Altai Mountains, Xinjiang, northwestern China. Quaternary Science Reviews, 152: 19-30.

Zhou G, Wang Y, Jiang Y, et al. 2002. Estimating biomass and net primary production from forest inventory data: a case study of China's Larix forests. Forest Ecology and Management, 169(1-2): 149-157.

Zhou X, Brandle J R, Schoeneberger, et al. 2007. Developing above-ground woody biomass equations for open-grown, multiple-stemmed tree species: Shelterbelt-grown Russian-olive. Ecological Modelling, 202(3-4): 311-323.

Zianis D, Mencuccini M. 2004. On simplifying allometric analyses of forest biomass. Forest Ecology and Management, 187(2-3): 311-332.

Zianis D, Muukkonen P, Maekipaeae R, et al. 2005. Biomass and stem volume equations for tree species in Europe. Silva Fennica Monographs, 4(4): 1-63.

Zianis D, Xanthopoulos G, Kalabokidis K, et al. 2011. Allometric equations for aboveground biomass estimation by size class for Pinus brutia Ten. trees growing in North and South Aegean Islands, Greece. European Journal of Forest Research, 130(2): 145-160. 